Recebido: $12 / 06 / 2018$

Aprovado: 24/07/2018

\title{
Pacifismo, educação e dimensões políticas na América Latina: Cecília Meireles em diálogo com Alfonso Reyes (Rio de Janeiro, década de 1930)
}

Denilson de Cássio Silva*

\section{Resumo:}

O artigo analisa as ideias em torno da questão da guerra e da paz, discutidas pela poetisa e jornalista carioca, Cecília Meireles, e Alfonso Reyes, embaixador do México no Brasil de 1930 a 1936. Tendo como principais fontes exemplares do Diário de Notícias, demonstra-se que ambos os intelectuais defenderam um pacifismo ativo, de tônica universalista, com base na valorização de uma educação nova e do protagonismo da América Latina.

Palavras-chave: Política; Cecilia Meireles; Alfonso Reyes.

\section{Abstract:}

The article analyzes the ideas on the question of war and peace, discussed by the poet and journalist from Rio de Janeiro, Cecília Meireles, and Alfonso Reyes, ambassador of Mexico in Brazil from 1930 to 1936. Having as main sources the exemplares of Diário de Notícias, it is demonstred that both intellectuals defended an activist pacifism with universalistic tone, based on the valorization of a new education and the Latin America protagonism.

Keywords: Politics; Cecília Meireles; Alfonso Reyes.

\footnotetext{
* Professor do Departamento de Geografia e História do Centro Federal de Educação Tecnológica de Minas Gerais (CEFET/MG). Doutorando do Programa de Pós-Graduação em História da UFMG. denicult@hotmail.com
} 


\section{Introdução}

No Brasil, no México e em outras partes do mundo, a década de 1930 foi marcada por contendas entre diferentes perspectivas diante do problema da guerra e da paz. Ao longo de suas trajetórias, Cecília Meireles e Alfonso Reyes incorporaram valores axiológicos e ventilaram projetos políticos, mediante a atuação na esfera pública. No intuito de identificar e analisar as principais ideias assumidas por esses intelectuais, compreendendo suas atitudes diante do fenômeno bélico e do papel das nações latinoamericanas, o presente artigo parte da hipótese de que o pacifismo ativo foi um dos pilares dos argumentos sustentados por aqueles. Portador de tonalidades universalistas, congruentes com os apelos da Sociedade das Nações, esse pacifismo estaria presente nas discussões sobre educação e cultura.

As fontes aqui utilizadas foram edições do jornal Diário de Notícias, no qual atuou Cecília Meireles. A metodologia adotada é de caráter qualitativo, bibliográfico e empírico. Efetuou-se uma revisão bibliográfica, indo da fortuna crítica sobre Cecília Meireles para a análise do diálogo estabelecido com Alfonso Reyes. Foram selecionadas oito crônicas e duas reportagens, cujos títulos e conteúdos contribuíssem de forma significativa para o exame proposto.

A base teórica é constituída, sobretudo, pelas concepções de política, de Hannah Arendt (2014; 2017), e de pacifismo ativo, de Norberto Bobbio (2003). Igualmente, a noção de cultura de guerra, proposta por Sílvia Correia (2015), perpassa o exame, como uma espécie de ferramenta heurística. Em linhas gerais, o artigo ocupa um lócus fronteiriço entre a História Política e do Político (RÉMOND, 2003; ROSANVALLON, 2010) e a História Cultural (BURKE, 2008).

Destarte, em um primeiro momento, é realizado um balanço bibliográfico. A seguir, emerge a análise sobre as interlocuções estabelecidas entre Cecília Meireles e Alfonso Reyes, com destaque para as ideias de paz e de educação, entendidas como dimensões do fenômeno político. Na sequência, têm-se as considerações finais, em que se tenta concatenar mais explicitamente as duas partes do artigo.

\section{Uma intelectual multifacetada}


Nascida em 7 de novembro de 1901, na cidade do Rio de Janeiro, Cecília Meireles, ao longo de sua trajetória intelectual ${ }^{1}$, veio a se tornar uma das maiores escritoras da língua portuguesa. Tal projeção foi tecida ainda em vida, ao longo de décadas de trabalho. Atuou como professora, poetisa, jornalista, cronista, tradutora, folclorista, estudiosa de povos orientais (NEVES et. al., 2001; GOUVÊA, 2007; LÔBO, 2010).

Não obstante esse caráter multifacetado, a crítica literária, por décadas, tendeu a se contentar com a ênfase nos traços do lirismo da obra ceciliana, seus contornos etéreos, sua autoimagem como "pastora de nuvens" (MEIRELES, 2001a: 292), seu suposto distanciamento da realidade ao redor (PAES, 1997). A difusão e o predomínio dessa perspectiva - elaborada durante e após a vida da autora, falecida em 9 de novembro de 1964 - foi tal que o estudo de outras ações e produções cecilianas ficaram destinadas a segundo plano e, quando lembradas, imbuídas da imagem da poetiza do "solilóquio lírico", do "ar diáfano", das "terras altas" (ibidem: 35-36). Esse quadro permitiu a Marisa Lajolo, por ocasião do centenário de nascimento da escritora, em 2001, ponderar que

[...] na timidez do registro e no quase-silêncio, o que se tem é a propagação em eco de juízos críticos que não costumam ir além de apontar a espiritualidade da poética ceciliana, na qual também se garimpam e se proclamam procedimentos neo-simbolistas e transfigurações sensoriais da história brasileira. (LAJOLO, 2001:13).

De acordo com Lajolo, o lugar de Cecília Meireles na história literária brasileira, embora incontornável, mostrava-se ainda tímido e espremido entre um "pós-isto (modernismo paulista, por exemplo [...]) e um pré-aquilo (por exemplo, modernidade [...])." (ibidem: 13).

Em 1996 dois trabalhos colaboraram para dar maior visibilidade à atuação de Cecília Meireles e chamaram a atenção para a importância de se percorrer outros caminhos investigativos. No artigo intitulado Memória e educação, Yolanda Lôbo explorou a tese da escritora, publicada em 1929, que viria a ser utilizada como requisito para concorrer à cátedra de literatura vernácula da Escola Normal do Distrito Federal

\footnotetext{
${ }^{1}$ Sobre o conceito de "intelectuais", tem-se em conta a fala de Jean-François Sirinelli, que propõe "uma definição de geometria variável, mas baseada em invariantes". Considera-se a acepção "ampla e sociocultural, englobando os criadores e os 'mediadores' culturais, [...] tanto o jornalista como o escritor, o professor secundário como o erudito" (SIRINELLI, 2003: 242). Para maiores discussões em torno dessa noção e de seu traço polimorfo, polifônico e polissêmico, cf. ALTAMIRANO, 2005; GOMES \& HANSEN, 2016. Quanto à intelectualidade do Rio de Janeiro, cf. GOMES, 1993.
} 
(LÔBO, 1996). Já Valéria Lamego expôs A farpa da lira (LAMEGO, 1996). Ambos os trabalhos sublinharam aspectos da intervenção pública de Cecília Meireles, distintos da visão de uma escriba distante e aérea. Especialmente, a devassa de Lamego trouxe à tona o exercício de uma escritora combativa, resoluta no enfrentamento de temas controvertidos em sua coluna do Diário de Notícias (LAMEGO, 1996). Essas duas pesquisas tiveram como fonte principal de investigação, textos em prosa, mas os questionamentos ali sublinhados poderiam ressoar na avaliação dos poemas.

Nessa direção, vale evocar uma pista deixada pelo exegeta da obra ceciliana, Darcy Damasceno. Escrevendo originalmente em 1958, sobre a poesia, Damasceno observava que:

O conjunto de seres e coisas que latejam, crescem, brilham, gravitam, se multiplicam e morrem, num constante fluir, perecer e renovar-se, e, impressionando-nos os sentidos, configuram a realidade física, é gozosamente apreendida por Cecília Meireles, que vê no espetáculo do mundo algo digno de contemplação - de amor, portanto. (DAMASCENO, 1972: 17).

O mundo, a referencialidade, os seres e as coisas, segundo o estudioso, integravam o universo lírico-poético de Cecília Meireles, que se erigia em comunicação com as experiências sociais, políticas, culturais e econômicas de seu tempo. Em 1973, seguindo o filão sinalizado por Damasceno, Eliane Zagury empregaria expressões como "encruzilhada participante" e "em busca da participação isenta" para apreciar as características da poesia de Cecília Meireles e romper com o rótulo de "alienada", atribuído à poetisa por parte de determinados críticos (ZAGURY, 1973: 45-50).

Mais tarde, em 1998, a percepção de que a poesia de Cecília Meireles envolvia mais nuances do que consentia a estampa de neossimbolista, tomou outro patamar com a pesquisa de doutorado de Murilo Marcondes de Moura. O autor (1998) investigou os impactos da Segunda Guerra Mundial na poesia de Carlos Drummond de Andrade, Cecília Meireles e Murilo Mendes, demonstrando que também a criação poética da autora carioca, continha elementos confrontados pelo drama da guerra.

No mesmo ano de 1998, ao apresentar o primeiro volume da Obra em Prosa de Cecília Meireles, Leodegário de Azevedo Filho asseverou que o estilo da autora nos textos ali reunidos "afasta-se do espírito de reportagem, conferindo alto valor literário às suas crônicas, sempre perplexa diante do espetáculo da vida, dos seres e das coisas, mas 
também revoltada, às vezes, contra o desconcerto do mundo e as injustiças sociais" (AZEVEDO FILHO, 1998: X-XI).

Fazendo eco a esse movimento de revisão da obra ceciliana, o ano de 2001 pode ser considerado um ponto de inflexão. Ocorreram eventos e publicações que fomentaram o esquadrinhamento da plurivalência da intelectual. Ana Maria de Oliveira apresentou um importante estudo (OLIVEIRA, 2001), referenciando dados e informações, antes dispersos. Margarida Neves, Yolanda Lôbo e Ana Mignot articularam trabalhos de diferentes estudiosos (NEVES et. al., 2001). Nessa obra, a diversidade da homenageada verteu capítulos dedicados, por exemplo, às atuações nos âmbitos da educação, da poesia, da literatura infantil, do folclore, da crônica e da prática missivista. Em diapasão semelhante, ainda em 2001, realizou-se o Seminário Internacional Cecília Meireles, na Universidade de São Paulo. Parte expressiva das apresentações ali discutidas seria reunida e organizada por Leila Gouvêa, no ano de 2007 e também traçaria um variado painel das atividades cecilianas (GOUVÊA, 2007). Por fim, cabe apontar a publicação da Poesia Completa (MEIRELES, 2001 a), em dois volumes, e grande parcela das Crônicas de Educação, em cinco (MEIRELES, 2001, b).

No decorrer das décadas de 2000 e 2010, mais pesquisas surgiram, adensando os saberes acerca de suas viagens (GOUVÊA, 2001; PIMENTA, 2008; ROMANO, 2014), dos elos com a Índia (MARCHIORO, 2014; MELLO \& UTÉZA, 2006; OLIVEIRA, 2014), da experiência de tradução (REIS, 2015), das ideias e lutas educacionais (CUNHA \& SOUZA, 2011; SOARES, 2007; STRANG, 2003; VIEIRA, 2013), da literatura feminina (SILVA, 2012) dentre outros ${ }^{2}$.

O problema do pacifismo, assumido por Cecília Meireles, entretanto, vem sendo apenas tangenciado, sobretudo, em trabalhos que ora discutem as influências indianas em suas ideias (OLIVEIRA, 2014); ora abordam sua atuação de cronista ou de poetisa ante a Segunda Guerra Mundial, como, respectivamente, a dissertação de Daniela Alves (2012), e o livro de Murilo Marcondes de Moura (2016). Em nenhum desses estudos o problema da paz e da guerra no pensamento, nas intervenções e nas elaborações artístico-culturais de Cecília Meireles, durante os anos 1930, é tratado de modo a se ultrapassar a constatação da afinidade intelectual da mesma com Gandhi, Tagore e com valores pacifistas, mais ou menos difusos.

\footnotetext{
${ }^{2}$ Muitos desses aspectos entrecruzam-se nas obras citadas. Cf. também OLIVEIRA \& LOPES, 2014. 
De modo análogo, a postura de Cecília Meireles ante a situação e as potencialidades da América Latina, vem sendo interrogada em trabalhos como os de Jacicarla Silva (2012), que analisa a atuação de mulheres intelectuais no cenário cultural e literário; e os de Fred Elllison (2002), Regina Crespo (2003), Natally Dias (2013) e Angela Norte (2013). Estes últimos, em sentido inverso ao de nossa pesquisa, dirigem a análise para a trajetória e a atuação político-cultural de Alfonso Reyes, aludindo-se, em certas passagens, à interlocução deste com Cecília Meireles.

Pensa-se que tais estudos não examinaram mais detidamente o pacifismo, enquanto elemento político aglutinador e de tomada de posição na cena pública, porque não tinham esse fenômeno como cerne de interesse investigativo e também por não haver considerado as especificidades dos anos 1930, marcados por determinadas culturas de guerra.

\section{Pacifismo, política, educação}

A noção de cultura de guerra alude, segundo Sílvia Correia, a "um conjunto de ferramentas mentais às quais homens e mulheres contemporâneos ao conflito lançaram mão para o tornar inteligível, dar-lhe sentido" (CORREIA, 2013: 30). "Conflito" alusivo às interrogações provocadas pela Grande Guerra (1914-1918), as quais, porque heteróclitas, geravam diferentes gramáticas interpretativas. Por isso, “[...] Mais do que falar em 'cultura de guerra', devemos falar em 'culturas de guerra"' (ibidem: 50), no plural. A temática da guerra e da paz constituía um dos assuntos mais recorrentes e sensíveis desse período. O wilsonismo, a criação da Liga das Nações, em 1919, e da Comissão Internacional de Cooperação Intelectual, reunida em 1922, os Acordos de Locarno, assinados em 1925, e os Cursos Universitários de Davos, realizados nos anos de 1928 a 1931 (EINSTEIN, 2016; WALTERS, 1952), ecoavam pela imprensa e por meios intelectuais latino-americanos (CERVO, 2008; REYES, 1996).

Tende-se, pois, a corroborar a hipótese de Olivier Compagnon, segundo a qual a Grande Guerra tornou-se uma referência basilar não só para a Europa, como também para a América Latina. No decorrer do que José Ingenieros chamou de "o suicídio dos bárbaros" (INGENIEROS, 1921: 12) e após o armistício de novembro de 1918, vários foram os intelectuais que se viram às voltas com o repensar sobre o seu estar-no-mundo. As sociedades brasileira, argentina e - seria possível acrescentar - mexicana, cada qual a 
seu modo, estavam diante de uma Europa que se autodestruíra, sacudindo a arraigada imagem de centro e de modelo de civilização para o mundo (COMPAGNON, 2014).

Cecília Meireles e Alfonso Reyes, ao se situarem como intelectuais, participavam de uma aguda percepção comum de indefinições. ${ }^{3}$ Tempo em que se punham à mostra uma onda de questionamentos sobre o passado, de debates sobre a mudança de paradigmas em diversas áreas. As vanguardas modernistas, a vacilação da democracia liberal, o avanço do fascismo, os preceitos do socialismo-comunismo, amalgamavam-se em anos de grande agitação (FERREIRA \& DELGADO, 2015; HOBSBAWM, 1995).

Naquela passagem das décadas, tanto o México revolucionário, sob a influência de Elias Calles, quanto o Brasil da Revolução de 1930, com Getúlio Vargas à frente, eram países marcados por experiências e expectativas em torno do devir desses povos ${ }^{4}$. Em tais circunstâncias, muitos intelectuais, retomando ideias precedentes, conferiam a si tarefas de atuar em prol da sociedade (SEVCENKO, 2003; VELLOSO, 2010).

Em suma, pode-se inferir que

o apelo ao pensamento surgiu no estranho período intermediário que por vezes se insere no tempo histórico, quando não somente os historiadores futuros, mas também os atores e as testemunhas, os vivos mesmos, tornam-se conscientes de um intervalo de tempo totalmente determinado por coisas que não são mais e por coisas que não são ainda. (ARENDT, 2013: 35-36).

Entre o passado e o futuro, entre o não mais e o ainda não, expressões que, se tomadas a rigor, poderiam se prestar à análise de distintos períodos históricos, não por acaso foram acionadas por Hannah Arendt para pensar o ínterim de 1914 a 1945, tempo vivido por Cecília Meireles e Alfonso Reyes.

Nascido em 17 de maio de 1889, ex-integrante do Ateneu da Juventude (19091912), no México, poeta, ensaísta e diplomata, Reyes foi nomeado embaixador no Brasil, onde chegou em abril de 1930. Instalando-se no Rio de Janeiro, exerceu a função até 1936 e entabulou contatos com uma rede de intelectuais, dentre os quais se encontravam

\footnotetext{
${ }^{3}$ Em relação à cronologia, ora abarcada, percebe-se que também os anos 1920 foram cruciais para as vivências de culturas de guerra e a busca por respostas para os problemas ligados ao conflito. Cf. FUNES, 2006.

${ }^{4}$ Para os conceitos de espaço de experiência e horizonte de expectativa, cf. KOSELLECK, 2006.
} 
Ronald de Carvalho, Manuel Bandeira, Alceu Amoroso Lima, Ana Amélia de Mendonça e Cecília Meireles (ELLISON, 2002; NORTE, 2013)

Essa última, de junho de 1930 a janeiro de 1933, dirigiu a Página de Educação do Diário de Notícias na então Capital Federal. Ao ocupar tal espaço, fortemente masculinizado ${ }^{6}$, Cecília Meireles voltou sua atenção para questões educacionais do Brasil e do mundo e, através dessa lente, discorreu sobre os mais variados assuntos ${ }^{7}$.

Em 06 de março de 1931, em sua coluna Comentário, publicou um texto, cerzindo considerações sobre a obra de Reyes, El testimonio de Juan Pena, então recém-editada no Rio de Janeiro e norteada por memórias de juventude ${ }^{8}$. Cecília Meireles julgou o livro importante, de um "artista finíssimo", capaz de despertar o interesse do leitor, devido ao apuro estético e à abordagem de um tema caro aos que se preocupavam com a educação, com a "psicologia juvenil”, ou seja, com o "problema humano" de uma idade na qual "se é livre e se tem pela liberdade um excepcional amor", em que "se ouve cada resposta como uma nova pergunta" (ibidem).

Dias depois, em 15 de março, voltando sua atenção para o país de origem de Alfonso Reyes, publicou $O$ exemplo do México, em que tratava das reformas educacionais, impulsionadas com o governo Calles, fundadas em valores de uma educação moderna, preocupada com a humanização do ser humano, com o desenvolvimento de aptidões adequadas às necessidades de cada indivíduo e a superação das desigualdades sociais ${ }^{9}$.

No ano seguinte, as articulações de Cecília Meireles com a história do México e seu embaixador no Brasil, dariam vazão a pelo menos seis crônicas, em que estabeleceria diálogo direto com Alfonso Reyes e/ou tornava a enaltecer aquela nação. Os títulos desses comentários são sugestivos, como se vê, em ordem cronológica: Fraternidade, Sobre um discurso de Alfonso Reyes, “Atenea Política”, Para Alfonso Reyes, Esse glorioso México

\footnotetext{
${ }^{5}$ Sobre a relação de Alfonso Reyes com José Vasconcelos e com o Brasil, ainda na década de 1920, cf. CRESPO, 2003.

${ }^{6}$ Ao comandar a Página de Educação, Cecília Meireles desafiava enquadramentos culturais comezinhos, vivenciando as determinações e ambiguidades de ser mulher naquele contexto. Cf. LOURO, 2011; TELLES, 2011; SILVA, 2009; 2012.

${ }^{7}$ Para informações sobre o Diário de Notícias, seus proprietários e sua linha editorial, cf. LÔBO, 2010; DIÁRIO, 2018.

${ }^{8}$ MEIRELES, Cecília. Uma recordação da juventude. Diário de Notícias. Rio de Janeiro, 06 mar. 1931:6.

${ }^{9}$ MEIRELES, Cecília. O exemplo do México. Diário de Notícias. Rio de Janeiro, 15 mar. 1931: 6. A autora alinhava-se ao escolanovismo internacional e veio a se tornar uma das principais representantes dessa corrente político-educacional no Brasil. Cf. MORAES, 2007.
} 
e A extensão das pátrias $^{10}$. Simultaneamente foi feita uma ampla cobertura jornalística relativa a duas participações públicas de Reyes.

Datado do dia 23 de janeiro de 1932, o primeiro artigo, Fraternidade, concatenava o tema das relações internacionais com a obra educacional, tendo em vista a superação dos ódios raciais, religiosos e chauvinistas. Nos termos da autora,

Não obstante a terra ser tão pequena, ainda somos quase todos estrangeiros, uns para os outros. As raças e as religiões têm sido as distâncias mais invencíveis para o convívio de que carecemos. E quando as criaturas ouvem dizer que são irmãs, há uma espécie de incredulidade, muitas vezes. Serão mesmo? E, para começar, o ocidente recorda o oriental, e sorri. O ariano lembra-se do fundo da África, e reflete... ${ }^{11}$

Nota-se que o idealismo de Cecília Meireles estava associado à alternativa de uma humanidade acolhedora de alteridades e fincava raízes no exercício do espírito crítico. $\mathrm{O}$ real não serviria para forçar a rendição ao fatalismo conformista, cético em face do potencial dos humanos para a convivência pacífica, e, sim, para demonstrar a necessidade de mudança da história. Caberia, diante de preconceitos direcionados aos povos orientais, de mitos arianos, lutar para que houvesse no "mundo inteiro uma transformação que o humanize", tornando-o capaz de ver "a cada um mais além do horizonte de sua geografia" (ibidem). A obra educacional constituiria o alicerce para tal ruptura, não se propondo a "reduzir todas as criaturas vivas a um determinado padrão". Ao invés disso, buscava-se um "equilíbrio [...] feito de desigualdades que se harmonizam". Desigualdades apreendidas, nesse trecho, como singularidades, que "fecundam-se, inspiram, sugerem, atraem" (ibidem).

A escritora encerrou a crônica, confessando: "Estive pensando tudo isso porque Alfonso Reyes, essa interessantíssima personalidade [...], me disse que vai ver se é possível que, com a exposição mexicana a realizar-se [...] aqui, venha uma seção de arte infantil”. E arrematou: “[...] que se passará na alma das crianças brasileiras cujos olhos se encontrarem com a alma de seus irmãozinhos lá de longe, tão surpreendente e tão bela?

\footnotetext{
${ }^{10}$ Sobre um discurso de Alfonso Reyes, "Atenea Política" e Para Alfonso Reyes foram comentados por ELLISON, 2002, o qual, contudo, não se ateve aos aspectos que nos parecem fundamentais, ou seja, a ação política, o pacifismo e a educação. O mesmo vale para $O$ exemplo do México, arrolado por SILVA, 2012.

${ }^{11}$ MEIRELES, Cecília. Fraternidade. Diário de Notícias. Rio de Janeiro, 23 jan. 1932:6.
} 
(ibidem). A aproximação cultural, intermediada pela educação e pela arte, seria um passo concreto na configuração de uma nova vida.

Tal concepção infiltraria, continuamente, Sobre um discurso de Alfonso Reyes, de 16 de abril, assim como "Atenea Política" e Para Alfonso Reyes, respectivamente, de 03 e 04 de maio de 1932.

O discurso proferido por Alfonso Reyes no Teatro João Caetano, por passagem das comemorações do Dia Pan-Americano, em 14 de abril ${ }^{12}$, ganhou destaque dois dias depois, na edição do dia $16^{13}$. Ocupando o centro da Página de Educação, o título e os subtítulos dados à matéria foram assim sequenciados: “Alfonso Reyes. O intercâmbio universitário e a obra da paz. Palavras do embaixador do México na comemoração do Dia Pan-Americano" "14. Abaixo desses dizeres, colocou-se uma fotografia de Reyes com a legenda "Alfonso Reyes, no seu gabinete de trabalho" (ibidem). A imagem mostrava o diplomata-escritor sentado à mesa, manuseando papeis, com um olhar firme no horizonte, tendo uma estante com livros ao fundo. Palavras e retrato pareciam querer inspirar nos leitores admiração por um intelectual, comprometido com os estudos e com ideais pacifistas.

Na ocasião, Alfonso Reyes discorreu sobre as juventudes universitárias, a vida intelectual, a união entre as Américas e a obra da paz, enfatizando o protagonismo dos estudantes e da cooperação intelectual, como fundamentos para a materialização das ações e dos princípios defendidos pelo Instituto Internacional de Cooperação Intelectual, órgão vinculado à Sociedade das Nações ${ }^{15}$. Grande parte dessa fala foi ali transcrita, ao

\footnotetext{
${ }^{12}$ De acordo com informações trazidas na seção $O$ momento internacional, o Governo Provisório de Vargas instituiu, no Brasil, pelo decreto ${ }^{\circ}$ 19.685, de 10 de fevereiro de 1931, o Dia Pan-Americano, visando à exaltação do "espírito de cordialidade continental". Cf. Diário de Notícias. Rio de Janeiro, 14 abr. 1932:2. ${ }^{13}$ Compondo a mesa com Alfonso Reyes e também dissertando sobre a "obra de pacificação entre os povos" e a "confraternização americana", estavam Afrânio de Mello Franco, ministro do Exterior, primeiro a discursar; dra Orminda Bastos, cuja fala sucedeu à de Alfonso Reyes; dr. Barbosa Lima Sobrinho, da Associação Brasileira de Imprensa; e, fazendo a última intervenção, Xavier de Oliveira, da Associação Brasileira de Educação. Essas informações endossam a hipótese de que havia uma cultura de guerra, ou seja, uma comunidade de ideias e de valores ético-morais, que punham o problema da paz no centro das preocupações e, ao fazê-lo, desenvolvia um repertório de termos, temas e conceitos. Ainda não tivemos acesso à transcrição dos demais discursos. Apenas a fala de Alfonso Reyes ganhou destaque na Página de Educação, fato que sugere a afinidade de Cecília Meireles com o mexicano.

${ }^{14}$ ALFONSO Reyes. O intercâmbio universitário e a obra da paz. Diário de Notícias. Rio de Janeiro, 16 abr. 1932:6.

${ }^{15}$ Reyes referiu-se ao Comitê Permanente de Letras e Artes - ligado ao Instituto Internacional de Cooperação Intelectual - que, naquele momento, estimulava a troca de correspondências entre intelectuais, acerca de temas de interesse geral dos povos. Partícipes da iniciativa, Albert Einstein, em julho de 1932, endereçou a pergunta "Por que a guerra?", a Sigmund Freud, que respondeu em setembro do mesmo ano. Cf. EINSTEIN, 2016; FREUD, 2010; CERVO, 2008; WALTERS, 1952. Para a participação oficial do Brasil em tais organismos internacionais, cf. DUMONT, 2016; RESENDE, 2013.
} 
lado do Comentário de Cecília Meireles, que sublinhou elogios e confluências políticas e culturais com o ilustre mexicano.

A diretora da Página reproduziu, em seu texto Sobre um discurso de Alfonso Reyes, as seguintes palavras, recém-proferidas por aquele: "Não nos conhecemos. A antologia dos erros que cometemos em matéria de informação precisa, quando falamos uns com os outros, envergonharia o Continente"16. Essa crítica de Reyes encarava um Brasil, cujas tradições políticas e culturais, desde o Império, pareciam tornar a América hispânica distante e estranha para os brasileiros ${ }^{17}$. Contudo, as reflexões do escritor sinalizavam também para as possíveis alterações em curso, ansiadas e incorporadas, igualmente, por Cecília Meireles:

De algum tempo para cá é muito agradável reconhecer que se desenvolveu uma efervescência de curiosidade mútua entre os escritores e os meios intelectuais de nossa América, singularmente entre os literatos e os poetas, que são, de todos os trabalhadores do espírito, os que operam com valores mais universais, os que abarcam maiores zonas da alma, e também aqueles cujo labor é mais vivaz e ostensível. Ouçam-nos bem os gagos que se vingam da palavra declarando-a impotente: este começo de solidariedade não foi produto do comércio nem da política de agora, mas da poesia, isto é, do espírito ${ }^{18}$.

Nesse trecho, traduzido, transcrito e citado por Cecília Meireles, nota-se que a ideia de atuação política extrapolava o nicho governamental-partidário, denotando, para esses intelectuais, mais eficácia na realização de mudanças históricas do que acordos econômicos e diplomáticos, regularmente imbuídos de desconfiança mútua ${ }^{19}$. O uso da

\footnotetext{
${ }^{16}$ Reyes. apud MEIRELES, Cecília. Sobre um discurso de Alfonso Reyes. Diário de Notícias. Rio de Janeiro, 16 abr. 1932:6.

${ }^{17}$ Maria Lígia Coelho Prado elenca dois momentos importantes em que se destacou a formação de um imaginário nacional em torno da "outra", da "distante" América hispânica. Foram eles as décadas seguintes à proclamação da independência política, em 1822, e os primeiros anos da república, proclamada em 1889. Analisando textos e comentários de diferentes intelectuais desses períodos, a autora avalia que "[...] eram duas Américas, uma da ordem, da paz e da unidade e a outra, do individualismo nefasto [...], do caos, da anarquia, da fragmentação. Mesmo em plena República, o imaginário sobre a identidade nacional combinava à ideia de unidade, a de ordem garantida pelo regime monárquico." (ibidem:144). A autora aponta também que, à corrente hegemônica de concepção em torno de uma "outra" América hispânica, opunham-se entendimentos mais matizados e favoráveis à aproximação do Brasil com os demais países latino-americanos, a exemplo de Manoel Bomfim, (ibidem: 140). Este seria professor de Cecília Meireles na Escola Normal do Distrito Federal, nos anos 1910.

${ }^{18}$ Reyes. apud MEIRELES, Cecília. Sobre um discurso de Alfonso Reyes. Diário de Notícias. Rio de Janeiro, 16 abr. 1932:6.

${ }^{19}$ No que tange ao ceticismo frente aos esforços diplomáticos para estabelecer a segurança internacional e o desarmamento, pode-se avaliar que a crise econômico-financeira, iniciada em 1929, a invasão da Manchúria pelo Japão, em 1931, e as intermináveis hesitações da Conferência de Desarmamento, ocorrida em Genebra, em 1932, marcaram esse início dos anos 1930. Tal desconfiança remontava à Conferência de
} 
palavra para o incremento do diálogo entre os povos, do pacifismo, da educação, seria tão decisivo quanto as jurisdições materiais e diplomáticas, investindo-se de legítima expressão política.

Tal aspecto coaduna-se com a concepção de política de Hannah Arendt ao afirmar: “(...) A política surge no entre-os-homens; portanto, totalmente fora dos homens. Por conseguinte, não existe nenhuma substância política original. A política surge no intraespaço e se estabelece como relação" (ARENDT, 2017: 23). Para Arendt, a política baseia-se na pluralidade dos seres humanos, na convivência entre diferentes, na participação ativa junto à vida coletiva. ${ }^{20}$ Todo ato público, assim, seria político por definição, porque posto e exposto à apreciação dos outros ${ }^{21}$. A atividade de escrita e o envolvimento com a imprensa, desse ângulo, constituem ações políticas, que recomendam e discutem demandas comuns.

Ao se examinar as atuações de Cecília Meireles e de Alfonso Reyes é verificado que os dois investiam suas energias nos embates travados na esfera pública ${ }^{22}$, por meio do uso da palavra, captada como "um sentido de ato e não só de reflexão" (CASTRO, 2018: 17).

Paz de 1919, que culminara com a assinatura do Tratado de Versalhes. Cf. CERVO, 2008: 131-167; NOGUEIRA \& MESSARI, 2005: 20-104.

${ }^{20}$ Essa concepção parece guardar similitudes com o conceito de "político", assinalado por Pierre Rosanvallon, que o descreve como "o lugar em que se entrelaçam os múltiplos fios da vida dos homens e mulheres; aquilo que confere um quadro geral a seus discursos e ações", remetendo "à existência de uma 'sociedade' que, aos olhos de seus partícipes, aparece como um todo dotado de sentido" (ROSANVALLON, 2010: 71).

${ }^{21}$ Para Hannah Arendt, o fenômeno da política diferir-se-ia, por um lado, do espaço privado, identificado como o âmbito do não exercício da política, porque adstrito ao interesse individual, supostamente desinteressado pela experiência do comum; e, por outro, do estatismo totalitário, cuja esfera social, massificada, aniquilaria a liberdade, sem a qual não haveria vida política. Em suma, tanto o extremo individualismo burguês, quanto o terror e a ideologia totalitários encarnariam a negação da política (ARENDT, 2012; 2014; 2017). Cabe assinalar que se concorda com a autora no que concerne ao fator fundamental de atuação no domínio público, mediante o exercício da fala, para a definição de uma ação política. Sob essa ótica, as discussões encetadas por Cecília Meireles e Alfonso Reyes mostram-se, vigorosamente, políticas. Ao mesmo tempo, faz-se a ressalva de que uma das limitações da análise de Hannah Arendt seja, talvez, o risco de se demarcar, rigidamente, o que é político e o que não o é. Compreende-se que essa distinção talvez seja mais fluída e cambiante do que as categorias arendtianas, inspiradas nos gregos antigos, possam sugerir. Assim, aproveitando as contribuições da pensadora alemã, atenta-se também para os aspectos políticos e simbólicos do social e das relações pessoais dos agentes históricos. Nesse sentido, tendemos a nos aproximar do diálogo crítico estabelecido por Claude Lefort (1991) com o pensamento político de Hannah Arendt.

${ }^{22} \mathrm{O}$ conceito de esfera pública tem a acepção de "uma rede adequada para a comunicação de conteúdos, tomadas de posição e opiniões; nela os fluxos comunicacionais são filtrados e sintetizados, a ponto de se condensarem em opiniões públicas, enfeixadas em temas específicos" (HABERMAS, 2011: 93. Itálicos originais). Sob uma ótica mais abrangente, considera-se igualmente válido o conceito de "domínio público", de Hannah Arendt, compreendido como "mundo comum", que nos reúne "na companhia uns dos outros e, contudo, evita que caiamos uns sobre os outros, por assim dizer" (ARENDT, 2014:65).

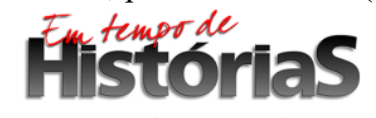

(PPGHIS/UnB) №. 32, Brasília, Jan - Jul 2018 ISSN 2316-1191 
Em seu segundo discurso, coberto pela Página, agora realizado no salão nobre do Itamaraty, em 04 de maio, Reyes retomou os temas do intercâmbio universitário e intelectual e do caminho para a paz. Essa conferência resultara de um convite, feito por estudantes brasileiros do Clube da Reforma da Faculdade de Direito, do Rio de Janeiro, para falar sobre "o intercâmbio espiritual de todos os países", traçando um "panorama da fraternidade universal" 23 .

Um dia antes do evento, Cecília Meireles, ao manifestar apoio à iniciativa, em “Atenea Política”, situou o México na América do $\mathrm{Sul}^{24}$. Advogando que a educação elevava-se como problema-chave daqueles tempos, a jornalista redigiu:

Na América do Sul, o México tem, efetivamente, uma fisionomia própria, em todos os seus aspectos. O aspecto educacional vem sendo, desde muito, aquele em que todos os outros se refletem, aquele que a todos sintetiza; e por ele se pode julgar do rumo que segue o pensamento geral de uma época e a inquietude dos homens que a habitam. (ibidem)

No dia seguinte, em que se realizaria a conferência, a cronista ofereceu seu texto Para Alfonso Reyes, analisando a razão do equívoco geográfico, que, ao final das contas - explicava - revelou-se correto, porque “(...) As terras pode ser que estejam em lugares fixos; mas os povos estão onde os coloca o interesse de quem os contempla: estão mais longe ou mais perto, na relatividade do pensamento e do coração" ${ }^{25}$. Se o que comandava aquele texto eram "rápidas linhas de entusiasmo" (ibidem), sim, o México haveria de estar ao sul do continente, bem próximo do Brasil. À artificialidade das fronteiras cartográficas nacionais, responderia o cultivo de uma mentalidade aberta à universalidade humana.

O "entusiasmo" novamente reverberou na crônica Esse glorioso México, de 06 de outubro. Cecília Meireles, então, considerou que a "prova de preocupação educacional de um povo" estava além de leis e de iniciativas do ensino, transbordando-se em atitudes que, "mesmo fora das órbitas escolares", coincidiam e confirmavam os ideais da educação ${ }^{26}$. Assim, se no plano educacional, o México engendrou "atividades altamente

\footnotetext{
${ }^{23}$ Essas duas citações foram extraídas da seção Movimento Universitário, junto à Página de Educação do dia 03 de maio de 1932: 6.

${ }^{24}$ MEIRELES, Cecília. “Atenea Política”. Diário de Notícias. Rio de Janeiro, 03 mai. 1932:6. O título dessa crônica seria o mesmo do discurso de Reyes, no dia seguinte.

${ }^{25}$ MEIRELES, Cecília. Para Alfonso Reyes. Diário de Notícias. Rio de Janeiro, 04 mai. 1932:6.

${ }^{26}$ MEIRELES, Cecília. Esse glorioso México. Diário de Notícias. Rio de Janeiro, 06 out. 1932:6.
} 
significativas, voltadas para a formação popular como objetivo sistemático" ${ }^{27}$, essa obra "luminosa e forte" representava "o programa do destino de um povo" (ibidem). Programa este que "seria bem precário se não viesse acompanhado de outras afirmações nacionais, que lhe dessem autenticidade, que lhe servissem de fundamento [...]" (ibidem). A atitude do México a que se referia como "tão esclarecida e coerente que, por ela, todos os seus pressupostos educacionais se sentem reafirmados", era uma resolução adotada pelo Governo de "não reconhecer direitos à conquista pela violência que for feita em território americano”. Resolução que, segundo Cecília Meireles, “está em harmonia com a outra”, de fundo cultural-educacional, "que é, por assim dizer, a sua forma de aplicação concreta, de tal modo é também violência e barbárie a posse dos invioláveis territórios do pensamento humano" (ibidem).

Nos parágrafos seguintes foi celebrada a entrada do México para o Conselho da Sociedade das Nações, em um "momento de dúvidas, de incertezas, de vacilações gerais do mundo", no qual "o México, afirmando suas aspirações, tem um brilho que não é apenas superficial", mas que palpita "do fundo daquele coração de liberdade ardentemente batido pelo vento de tantas revoluções" (ibidem). Por tudo isso, prosseguiu a articulista, as expectativas sobre a atuação do México naquele conselho já partiam de realizações palpáveis de um país "criador de liberdade, de vida nova, de claridade de espírito e de paz" (ibidem).

Com efeito, naquele início de outubro, pouco mais de um ano após ser admitido na Sociedade das $\mathrm{Nações}^{28}$, o México foi eleito membro não permanente do Conselho da organização de Genebra ${ }^{29}$ e aprovou o princípio, recomendado pelo Uruguai, do não reconhecimento, pelos países americanos, de conquistas territoriais que provenham da agressão de um povo contra outro ${ }^{30}$. Viria, a partir de então, a se tornar um dos países

\footnotetext{
${ }^{27}$ Acerca da educação popular no México e no Brasil, cf. FERREIRA, 2014.

${ }^{28}$ A admissão do México na Sociedade das Nações ocorreu em setembro de 1931, através de um convite intermediado pelo governo republicano da Espanha. Até então, os governos mexicanos haviam se recusado em participar dessa organização, considerando-se o fato de seu país ter sido excluído da lista original de Estados-Membros, por um acordo firmado entre Grã-Bretanha e EUA. Cf. WALTERS, 1952: 462.

${ }^{29}$ Cf. Diário de Notícias, 04 out. 1932: 2. O Conselho da Sociedade das Nações era uma espécie de órgão executivo, que dirigia os assuntos da Assembleia, a qual reunia todos os Estados-Membros. Cf. WALTERS, 1952.

${ }^{30}$ Cf. Diário de Notícias, 08 out. 1932: 2.
} 
latino-americanos mais atuantes junto àquela Sociedade, confirmando parte das esperanças nele depositadas ${ }^{31}$.

Ao adjetivar o México de "glorioso", a cronista contrastou essa qualidade com o cenário de um Brasil e de mundo, percebidos como uma realidade varada por "dúvidas", "incertezas" e "vacilações", em que se entrelaçavam os ramos educacionais e políticos. E finalizou com a assertiva de que a fatiga dos que laboravam por uma Educação nova, vez por outra, era recompensado pelo estímulo de um exemplo como o daquele país, de "um homem ou um povo que exceda, subitamente, todos os sonhos que se iam modelando tão devagar" (ibidem).

Com uma entonação semelhante, cerca de dois meses depois, em 14 de dezembro de 1932, a autora carioca referiu-se ao raciocínio universalista de Alfonso Reyes, debatendo o tema da existência das pátrias e do patriotismo. A crônica iniciou-se com um relato:

A propósito da trasladação dos restos de Santos Dumont, devo a Alfonso Reyes uma recordação interessante: as últimas palavras do discurso com que o Pai da Aviação respondeu às saudações da festa improvisada no Pavilhão Armenonville, por ocasião do seu primeiro voo. Essas palavras foram: 'Carj'ai deux amours: mon Pays et Paris. ${ }^{32}$

A partir desse mote, Cecília Meireles discorreu acerca de um amor à pátria, aglutinado à humanidade, visto que "quem diz Paris diz, de algum modo, o mundo" (ibidem). Aquela frase, consoante a autora, simbolizava "o retrato do espírito nacional e universal" (ibidem). Novamente, relacionando seus ideais com os possíveis distúrbios existentes, afiançou:

É certo que entre estrangeiro e inimigo já se diluiu quase toda a sinonímia. Mas é também certo que, entre o homem e a terra, existem certas condições de acordo mútuo, sem o qual a vida se faz impossível. A terra espera do forasteiro, como este, igualmente, dela espera, uma compreensão e uma dádiva, que sejam as expressões da sua comunicabilidade. (ibidem. Itálico original).

\footnotetext{
${ }^{31}$ Observa-se que a análise de Cecília Meireles poderia ser interpretada como uma advertência à relação do Brasil com a Sociedade das Nações, rompida em 1926, após a Sociedade preterir a demanda do governo brasileiro em obter um assento permanente no Conselho. Cf. BARACUHY, 2006; DUMONT, 2017.

${ }^{32}$ Em tradução livre: “Tenho dois amores: meu País e Paris”. MEIRELES, Cecília. A extensão das pátrias. Diário de Notícias. Rio de Janeiro, 14 dez. 1932:6.
} 
Nessa e em outras passagens, manifesta-se um chamado ao espírito de fraternidade, de cooperação, de humanidade e de paz, opostas aos arrazoados belicistas ou xenofóbicos. Cecília Meireles e Alfonso Reyes, ao recordar com simpatia a frase de Santos Dummont, fortaleciam o imaginário pacifista e enfrentavam os silogismos dos adversários da proposta de paz universal e da concepção de humanidade, a exemplo do jurista e filósofo político alemão, Carl Schmitt ${ }^{33}$.

Desse ponto de vista, o sentido de patriotismo, vislumbrado por Meireles e Reyes, divergia daquele que explorava a "figura do inimigo estrangeiro nas manifestações nacionalistas", no intuito de "excitar a fé patriótica do povo" (DUTRA, 2012: 141). Pelo contrário, postulava-se que “[...] No dia em que se ama intensamente a terra da pátria, já se está começando a amar para além das fronteiras a terra dos outros homens em que ela e nós nos prolongamos" 34 . Para tanto, argumenta Cecília Meireles, faz-se necessária a realização de uma obra educativa que "revele às crianças o encanto de um mundo harmonioso, em que os estrangeiros saem de semelhante condição pelo amor que oferecem à terra que os acolhe" e, dessa maneira, "encontram, por onde passam, uma pátria que se continua sempre, e que não tem fim" (ibidem). Em suma: "Um espírito de paz, seguro e eficiente, surgirá de uma obra que se saiba realizar dessa maneira".

Cecília Meireles concluiu A extensão das pátrias lembrando ao leitor que "este Comentário (...) não seria feito, se nele não houvesse colaborado o pensamento de um mexicano" (ibidem). Se, por um lado, a jornalista contribuía para amplificar a voz de Alfonso Reyes, por outro, os pronunciamentos e os escritos deste incrementavam as discussões da Página de Educação. Desse modo, o colóquio entre esses intelectuais valiase da valorização das afinidades políticas e encarnava, na prática do uso da palavra em espaço público, seus respectivos discursos pacifistas e educacionais.

\section{Considerações finais}

\footnotetext{
${ }^{33}$ Em texto publicado, inicialmente, em 1927, Carl Schmitt identifica no par terminológico "amigoinimigo", o que entende como a "essência do político", ou seja, o "fenômeno do político só se pode conceber através da referência à possibilidade real do agrupamento amigo-inimigo [...]" (2015: 67). O autor rechaçou a ideia de humanidade, que, segundo ele, reduzir-se-ia a "um instrumento ideológico das expansões imperialistas particularmente utilizável e, na sua forma ético-humanitária, um veículo específico do imperialismo econômico" (ibidem: 98).

${ }^{34}$ MEIRELES, Cecília. A extensão das pátrias. Diário de Notícias. Rio de Janeiro, 14 dez. 1932:6.
} 
Recapitulando-se as linhas-mestras da fortuna crítica em torno da obra ceciliana, infere-se que, sem abrir mão da acuidade com a palavra, do lirismo e da espiritualidade, a escritora atuou politicamente em defesa de seus ideais, extrapolando a dicotomia entre alheamento e engajamento.

Como demonstrado, em meio a uma conjuntura assinalada por culturas de guerra, que percorriam diferentes instâncias da vida e do cotidiano, Cecília Meireles e Alfonso Reyes alinharam-se, criticamente, a uma visão normativa das relações internacionais e ao pacifismo ativo, caracterizado por "uma tomada de posição que engaja pessoalmente, como toda tomada de posição moral, aquele que o assume." (BOBBIO, 2003: 75). Pacifismo que busca resolver o problema central da "eliminação da guerra e [da] instauração de uma paz perpétua", movendo-se em três direções, "agindo sobre os meios", "sobre as instituições" ou "sobre os homens" (idem: 97. Itálico original). Respectivamente, ter-se-ia um pacifismo instrumental, voltado para os meios de se evitar a guerra, como o desarmamento; um pacifismo institucional, relativo às tensões entre a autoridade do Estado e o estabelecimento da paz mediante a criação e a atuação de organizações supranacionais ou mediante revoluções sociais; e o pacifismo finalista, ligado à reforma ético-moral do ser humano, à criação de uma disposição para a convivência pacífica, mediante uma pedagogia centrada na tolerância e no diálogo (ibidem: $97-108)^{35}$.

As ideias cecilianas e alfonsinas, ora analisadas, indicam que os diferentes realces do pacifismo se encontravam interligados na ação desses autores, ao demarcarem lugar na cena pública, criticar as justificações da guerra e defender meios, instituições e finalidades em prol da paz.

Tal posicionamento gerou críticas, por parte de amigos e de adversários, que os acusaram de se furtarem a tomar partido em determinadas polêmicas. A forma como defendiam valores humanistas, de caráter universal, foi vista, em dadas ocasiões, como indícios de alheamento às tensões internas, de idealismo fantasioso e mesmo de

\footnotetext{
35 Tanto Cecília Meireles quanto Alfonso Reyes, ao sustentarem uma argumentação de eixo pacifista, sinalizavam aversão aos dogmas do nazifascismo. Por meio dessa atitude, comungavam de determinados valores da luta antifascista comunista na América Latina, estudada por OLIVEIRA, 2015. Entretanto, ao mesmo tempo, também se mostravam autônomos em relação à doutrina partidária do comunismo. Sobre o desenvolvimento milenar das ideias pacifistas, seus contornos ético-religiosos e político-filosóficos, cf. NOUR, 2004; WALTERS, 1952.
} 
antipatriotismo $^{36}$. Essas críticas nem sempre se abriam ao diálogo ou não queriam compreender a perspicácia das concepções de pacifismo, educação e política de Cecília Meireles e Alfonso Reyes. Ambos, a seu modo, frisavam o compromisso com seus respectivos países de origem e se municiavam de valores humanistas. Ambos se aproximavam de um idealismo crítico, que apostava na transformação do ser humano, por meio da educação e dos intercâmbios culturais, do desarmamento e de instituições pacifistas, e não se furtavam a encarar os desafios e as desilusões da realidade. A base argumentativa empregada por esses intelectuais apresentou proximidades com $\mathrm{o}$ pensamento arendtiano sobre a ação política, manifestando a crença de que, a partir do uso da razão no espaço público, as pessoas poderiam lutar por outra história, avessa às injunções da guerra e atenta às interlocuções entre os povos da América Latina.

\section{Referências bibliográficas}

\section{Fontes primárias}

MEIRELES, Cecília. Poesia completa. Rio de Janeiro: Nova Fronteira: 2001 a. 2 vols. Crônicas de educação. Apresentação e planejamento editorial de Leogedário A. de Azevedo Filho. Rio de Janeiro: Nova Fronteira, 2001 b. 5 vols.

Jornal Diário de Notícias, Rio de Janeiro:

Crônicas de Cecília Meireles

Uma recordação da juventude, 06 mar. 1931:6.

O exemplo do México, 15 mar. 1931:6.

Fraternidade, 23 jan. 1932:6.

Sobre um discurso de Alfonso Reyes, 16 abr. 1932:6.

“Atenea Política”, 03 mai. 1932:6

Para Alfonso Reyes, 04 mai. 1932:6.

Esse glorioso México, 06 out. 1932:6.

A extensão das pátrias, 14 dez. 1932:6.

$\underline{\text { Notícias e reportagens }}$

\footnotetext{
${ }^{36}$ Para as críticas feitas a Alfonso Reyes, cf. NORTE, 2013. Para os ataques feitos a Cecília Meireles, cf. ANDRADE, 2007; LAMEGO, 1996. Para uma crítica geral, apregoada por partidários de uma interpretação de patriotismo, tendente ao sectarismo, cf. Nogueira. apud OLIVEIRA, 1980: 43.
} 
O momento internacional: o dia pan-americano, 14 abr. 1932:2.

Alfonso Reyes. O intercâmbio universitário e a obra da paz, 16 abr. 1932:6.

Movimento Universitário, 03 de maio de 1932: 6.

Guerra de conquista, 08 out. 1932:2.

Disponíveis em http://bndigital.bn.gov.br/hemeroteca-digital/ Acessos: 31 out. 2017 a 25 mar. 2018.

\section{Teses e dissertações}

ALVES, Daniela Utescher. A crônica de Cecília Meireles: uma viagem pela ponte de vidro do arco-íris. 188 f. Dissertação (Mestrado) - Universidade de São Paulo, Programa de Pós-Graduação em Literatura Brasileira, São Paulo, 2012

FERREIRA, Rosângela Veiga J. Entre leitores, bibliotecas, campos e jardins: Gabriela Mistral e Cecília Meireles em projetos de educação popular, México (1920) e Brasil (1930). $328 \mathrm{f}$. Tese (Doutorado) Universidade Federal de Juiz de Fora, Programa de Pós-Graduação em Educação, 2014.

MARCHIORO, Camila. Cecília Meireles e os símbolos do absoluto. 124 f. Dissertação (Mestrado) Universidade Federal do Paraná, Setor de Ciências Humanas Estudos Literários, Curitiba, 2014.

MORAES, José Damiro de. 386 f. Signatárias do manifesto de 1932: trajetórias e dilemas. Tese (Doutorado) - Universidade Estadual de Campinas, Faculdade de Educação, Campinas, 2007.

MOURA, Murilo Marcondes de. Três poetas brasileiros e a Segunda Guerra Mundial (Carlos Drummond de Andrade, Cecília Meireles e Murilo Mendes). Tese (Doutorado) - Universidade de São Paulo, Faculdade de Filosofia, Letras e Ciências Humanas, São Paulo, 1998.

OLIVEIRA, Gisele Pereira de. Cecília Meireles e a Índia: das provisórias arquiteturas ao "êxtase longo de ilusão nenhuma". 233 f. Tese (Doutorado) - Universidade Estadual Paulista, Faculdade de Ciências e Letras, Assis, São Paulo, 2014.

PIMENTA, Jussara Santos. As duas margens do Atlântico: um projeto de integração entre dois povos na viagem de Cecília Meireles a Portugal (1934). 374 f. Tese (Doutorado) - Universidade do Estado do Rio de Janeiro, Programa de Pós-Graduação em Educação, 2008.

REIS, Ana Amélia Neubern Batista dos. Cecília Meireles e a Índia: uma experiência de tradução. $137 \mathrm{f}$. Dissertação (Mestrado) - Universidade Federal de Minas Gerais, Faculdade de Letras, 2015.

RESENDE, José Armando Zema de. A cooperação intelectual internacional da Sociedade das Nações e o Brasil (1922-1938): dinâmicas de um processo. 146 f. Dissertação (Mestrado) - Universidade de Brasília, Programa de Pós-Graduação em História, Brasília, 2013.

SILVA, Jacicarla Souza da. Um (in) visible college ma América Latina: Cecília Meireles, Gabriela Mistral e Victoria Ocampo. 213 f. Tese (Doutorado) - Universidade Estadual Paulista, Faculdade de Ciências e Letras de Assis, 2012.

STRANG, Bernadete de Lourdes Streisky. Sob o signo da reconstrução - os ideais da Escola Nova divulgados pelas crônicas de educação de Cecília Meireles. Dissertação (Mestrado) - Universidade Federal do Paraná, Curitiba, 2003.

VIEIRA, Ana Paula Leite. Cecília Meireles e a educação da infância pelo folclore. 182 f. Dissertação (Mestrado) - Universidade Federal Fluminense, Instituto de Ciências Humanas e Filosofia, Niterói, 2013.

\section{Livros e artigos}

ALTAMIRANO, Carlos. Para un programa de historia intelectual y otros ensayos. Buenos Aires: Siglo XXI Editores, 2005.

ANDRADE, Oswald. Telefonema. São Paulo: Globo, 2007.

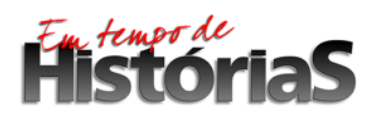

(PPGHIS/UnB) №. 32, Brasília, Jan - Jul 2018 ISSN 2316-1191 
ARENDT, Hannah. Origens do totalitarismo. Trad. Roberto Raposo. São Paulo: Companhia das Letras, 2012.

Entre o passado e o futuro. Trad. Mauro W. Barbosa. $7^{\text {a }}$ ed. São Paulo: Perspectiva, 2013.

2014. A condição humana. Trad. Roberto Raposo. 12a ed. rev. Rio de Janeiro: Forense Universitária,

O que é política? Trad. Reinaldo Guarany. 12ª ed. Rio de Janeiro: Bertrand Brasil, 2017.

AZEVEDO FILHO, Leodegário de. Apresentação. In: MEIRELES, Cecília. Obra em prosa: volume 1. Rio de Janeiro: Editora Nova Fronteira, 1998: IX-XIII.

BARACUHY, Braz. A crise da Liga das Nações de 1926: Realismo Neoclássico, Multilateralismo e a Natureza da Política Externa Brasileira. Contexto Internacional. Rio de Janeiro, vol. 28, nº 2, jul./dez. 2006: 355-397.

BOBBIO, Norberto. O problema da guerra e as vias da paz. Tradução Álvaro Lorencini. São Paulo: Editora UNESP, 2003.

BURKE, Peter. O que é história cultural? Tradução Sergio Goes de Paula. 2 ed. Rio de Janeiro: Zahar, 2008.

CASTRO, Susana de. O enigma de Hannah. Revista Cult. São Paulo. Ano 21, nº 9: 14 -17, 2018.

CERVO, Amado Luiz. A instabilidade internacional (1919-1939). In: SARAIVA, José Flávio Sombra (org.). História das relações internacionais contemporâneas: da sociedade internacional do século XIX à era da globalização. São Paulo: Saraiva, 2008:131-167.

COMPAGNON, Olivier. O adeus à Europa: A América Latina e Grande Guerra (Argentina e Brasil, 19141939). Tradução Carlos Nougué. Rio de Janeiro: Editora Rocco, 2014.

CORREIA, Sílvia. Entre heróis e mortos: políticas da memória da I Guerra Mundial em Portugal (19181933). Rio de Janeiro: 7 Letras: FAPERJ, 2015.

CRESPO, Regina Aída. Cultura e política: José Vasconcelos e Alfonso Reyes Reyes no- Brasil (19221938). Revista Brasileira de História. São Paulo. v. 23, nº 45: 187-208, 2003.

CUNHA, Marcus Vinícius da \& SOUZA, Aline Vieira de. Cecília Meireles e o temário da Escola Nova. Cadernos de Pesquisa. vol. 41. n. 144. set./dez. 2011, p. 850-865.

DAMASCENO, Darcy. Poesia do sensível e do imaginário. Notícia biográfica. Bibliografia In: MEIRELES, Cecília. Flor de poemas. 4. ed. Rio de Janeiro: Nova Fronteira, 1972: 9-57.

DIÁRIO de Notícias. Biblioteca Nacional Digital. Disponível em <https://bndigital.bn.gov.br/artigos/diario-de-noticias-rio-de-janeiro-1930/> Acesso em 16 fev. 2018.

DIAS, Natally Vieira. Diplomacia e atuação intelectual: Alfonso Reyes e a embaixada mexicana no Brasil (1930-1936). Temporalidades. Belo Horizonte. vol. 5, n. 1, jan./abr. 2013: 97-110.

DUMONT, Juliette. A América Latina na Sociedade das Nações: reflexões a partir do caso argentino, brasileiro e chileno. Tradução de Natália Guerellus. Revista escrita da historia. Ano III - vol. 3, n. 6, jul./dez. $2016 . \quad$ Disponível em <http://www.escritadahistoria.com/revista/index.php/escritadahistoria/article/view/143/75> Acesso em 15 mai. 2018.

DUTRA, Eliana de Freitas. O ardil totalitário: imaginário político do Brasil dos anos de 1930. 2. ed. Belo Horizonte: Editora UFMG, 2012.

EINSTEIN, Albert. Como vejo o mundo. Tradução H. P. de Almeida. Rio de Janeiro: Nova Fronteira, 2016.

ELLISON, Fred P. Alfonso Reyes e o Brasil: um mexicano entre os cariocas. Rio de Janeiro: Topbooks, 2002.

FERREIRA, Jorge \& DELGADO, Lucília de Almeida Neves (Org.). O tempo do nacional-estatismo: do início da década de 1930 ao apogeu do Estado Novo. $7^{\mathrm{a}}$ ed. Rio de Janeiro: Civilização Brasileira, 2015.

FILHO, Leogedário A. de Azevedo. Apresentação. In: MEIRELES, Cecília. Crônicas em geral. Rio de Janeiro: Nova Fronteira, 1998: XI-XII.

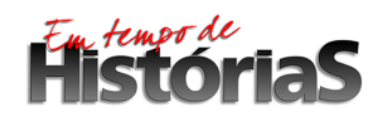

(PPGHIS/UnB) №. 32, Brasília, Jan - Jul 2018 ISSN 2316-1191 
FREUD, Sigmund. Por que a guerra? Carta a Einstein, 1932. In: O mal-estar da civilização, novas conferências introdutórias à psicanálise e outros textos (1930-1936). Tradução Paulo César Souza. São Paulo: Companhia das Letras, 2010: 415-435.

FUNES, Patrícia. Salvar la nación: intelectuales, cultura y política en los años 20 latinoamericanos. Buenos Aires: Prometeo Libros, 2006.

GOMES, Ângela de Castro. Essa gente do Rio... Intelectuais cariocas e o modernismo. Revista Estudos históricos. Rio de Janeiro, vol. 6, n. 11, 1993: 62-77.

\& HANSEN, Patrícia Santos (org.). Intelectuais mediadores: práticas culturais e ação política. Rio de Janeiro: Civilização Brasileira, 2016.

GOUVÊA, Leila V. B. Cecília em Portugal. São Paulo: Iluminuras, 2001. (org.). Ensaios sobre Cecília Meireles. São Paulo: Humanitas, 2007.

HABERMAS, Jürgen. Direito e democracia: entre facticidade e validade. Volume II. Trad. Flávio Beno Siebeneichler. Rio de Janeiro: Tempo Brasileiro, 2011.

HOBSBAWM, Eric. Era dos Extremos: o breve século XX, 1914-1991. Tradução Marcos Santarrita. São Paulo: Companhia das Letras, 1995.

INGENIEROS, José. O suicídio dos bárbaros. In: Os Tempos Novos: reflexões otimistas sobre a Grande Guerra e a Revolução Russa. Buenos Aires: Edições América Latina, 1921: 13-15.

KOSELLECK, Reinhart. Futuro passado: Contribuição à semântica dos tempos históricos. Trad. Wilma Maas; Carlos Pereira. Rio de Janeiro: Contraponto, 2006.

LAJOLO, Marisa. Prefácio. In: OLIVEIRA, Ana Maria Domingues. Estudo crítico da bibliografia sobre Cecília Meireles. São Paulo: Humanitas/USP, 2001: 13-15.

LAMEGO, Valéria. A farpa na lira: Cecília Meireles na Revolução de 30. Rio de Janeiro: Record, 1996.

LEFORT, Claude. Pensando o político: ensaios sobre democracia, revolução e liberdade. Tradução Eliana M. Souza. Rio de Janeiro: Paz e Terra, 1991.

LÔBO, Yolanda. Memória e educação: o Espírito Victorioso de Cecília Meireles. R. bras. Est. pedag., Brasília, v.77, n.187, p.525-545, set./dez. 1996.

Cecília Meireles. Recife: Fund. Joaquim Nabuco, 2010.

LOURO, Guacira Lopes. Mulheres na sala de aula. In: DEL PRIORI, Maria (org.). História das Mulheres no Brasil. 10. ed. São Paulo: Contexto, 2011: 443-481.

MELLO, Ana Maria Lisboa \& UTÉZA, Francis. Oriente e ocidente na poesia de Cecília Meireles. Porto Alegre: Libreto, 2006.

MOURA, Murilo Marcondes de. O mundo sitiado: a poesia brasileira e a Segunda Guerra Mundial. São Paulo: Ed. 34, 2016.

NEVES, Margarida de Souza; LÔBO, Yolanda Lima \& MIGNOT, Ana Chrystina Venancio (orgs.). Cecília Meireles: a Poética da Educação. Rio de Janeiro: Ed. PUC RJ: Loyola, 2001.

NOGUEIRA, João Pontes \& MESSARI, Nizar. Teoria das relações internacionais: correntes e debates. Rio de Janeiro: Elsevier, 2005.

NOGUEIRA, José Antônio. O ideal brasileiro desenvolvido na República. Apud: OLIVEIRA, Lúcia Lippi (cood.). Elite intelectual e debate político nos anos 30: uma bibliografia comentada da Revolução de 1930. Rio de Janeiro: Fundação Getúlio Vargas, 1980: 43.

NORTE, Angela Lopes. Alfonso Reyes: mexicano, intérprete do Brasil. Rio de Janeiro: 7 letras, 2013.

NOUR, Soraya. À paz perpétua de Kant: filosofia do direito internacional e das relações internacionais. São Paulo: Martins Fontes, 2004.

OLIVEIRA, Ana Maria Domingues. Estudo crítico da bibliografia sobre Cecília Meireles. São Paulo: Humanitas/USP, 2001.

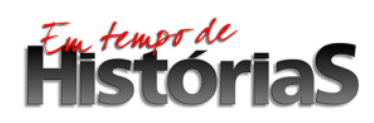

(PPGHIS/UnB) №. 32, Brasília, Jan - Jul 2018 ISSN 2316-1191 
OLIVEIRA, Ângela Meirelles de. Palavras como balas: imprensa e intelectuais antifascistas no Cone Sul (1933-1939). São Paulo: Alameda, 2015.

OLIVEIRA, Gisele de \& LOPES, Delvanir (org.). Cecília Meireles em diálogos ressonantes: 50 anos de presença em saudade (1964-2014). São Paulo: Scortecci, 2014.

PAES, José Paulo. Os perigos da poesia. Rio de Janeiro: Topbooks, 1997.

PRADO, Maria Lígia Coelho. O Brasil e a distante América do Sul. Revista de História. São Paulo, n.145 (2001): 127-149.

RÉMOND, René. Por uma história política. Trad. Dora Rocha. 2. ed. Rio de Janeiro: Editora FGV, 2003.

REYES, Alfonso. Obras completas de Alfonso Reyes. $2^{\text {a }}$ reimpressão. Tomo IX. Ciudad de Mexico: Fondo de Cultura Economica, 1996.

ROMANO, Luís Antônio Contatori. A poeta-viajante: uma teoria poética da viagem contemporânea nas crônicas de Cecília Meireles. São Paulo: Intermeios: 2014.

ROSANVAllon, Pierre. Por uma história do político. Trad. Christian Edward Lynch. São Paulo: Alameda, 2010.

SCHMITT, Carl. O conceito do político. Tradução Alexandre Franco de Sá. Lisboa: Edições 70, 2015.

SEVCENKO, Nicolau. Literatura como missão: tensões sociais e criação cultural na Primeira República. $2^{a}$ ed. São Paulo: Companhia das Letras, 2003.

SILVA, Jacicarla Souza da. Vozes femininas da poesia latino-americana: Cecília e as poetisas uruguaias [online]. São Paulo: Editora Unesp, 2009.

SIRINELLI, Jean-François. “Os intelectuais”. In: RÉMOND, René. Por uma História Política. 2. Ed. Rio de Janeiro: Editora FGV, 2003: 231-269.

SOARES, Gabriela Pellegrino. Semear horizontes: uma história da formação de leitores na Argentina e no Brasil, 1915-1954. Belo Horizonte: Editora UFMG, 2007.

TELLES, Norma. Escritoras, escritas, escrituras. In: DEL PRIORI, Maria (org.). História das Mulheres no Brasil. 10. ed. São Paulo: Contexto, 2011: 401-442.

VELLOSO, Mônica Pimenta. História e Modernismo. Belo Horizonte: Autêntica, 2010.

ZAGURY, Eliane. Cecília Meireles. Petrópolis: Vozes, 1973.

WALTERS, Francis P. A History of the League of Nations. Oxford: Oxford University Press, 1952. 